\title{
Mental health is correlated with lipoprotein(a) levels in male patients with premature coronary heart disease
}

\author{
Jinlan Bao ${ }^{1,2 \#}$, Shaoxin Zheng ${ }^{1,2 \#}$, Jingjing Huang ${ }^{1,2}$, Xiangkun Xie ${ }^{1,2}$, Jinglu Zhang ${ }^{3}$, Shiliang Yang ${ }^{3}$, \\ Xiaoying $\mathrm{Wu}^{1,2}$, Yuling $\mathrm{Zhang}{ }^{1,2}$ \\ ${ }^{1}$ Department of Cardiology, Sun Yat-sen Memorial Hospital, Sun Yat-sen University, Guangzhou, China; ${ }^{2}$ Guangzhou Key Laboratory of Molecular \\ Mechanism and Translation in Major Cardiovascular Disease, Sun Yat-Sen Memorial Hospital, Sun Yat-Sen University, Guangzhou, China; \\ ${ }^{3}$ Department of General Practice, Sun Yat-sen Memorial Hospital, Sun Yat-sen University, Guangzhou, China \\ Contributions: (I) Conception and design: J Bao, S Zheng; (II) Administrative support: Y Zhang; (III) Provision of study materials or patients: J Bao, \\ J Huang, X Xie; (IV) Collection and assembly of data: J Bao, J Huang, J Zhang, S Yang; (V) Data analysis and interpretation: J Bao, S Zheng; (VI) \\ Manuscript writing: All authors; (VII) Final approval of manuscript: All authors. \\ "These authors contributed equally to this work. \\ Correspondence to: Yuling Zhang. Sun Yat-sen Memorial Hospital, Sun Yat-sen University, No. 107, the West of Yanjiang Road, Guangzhou 510120, \\ China. Email: zhyul@mail.sysu.edu.cn.
}

Backgroundk High levels of lipoprotein(a) $(\operatorname{Lp}(a))$ is an independent risk factor for premature coronary heart disease (PCHD). It is also considered a residual risk for controlled low density lipoprotein cholesterol (LDL-C). Dietary control, exercise, and drugs have limited effects on the levels of Lp(a). Recently, mental health was found to be associated with lipid levels and increased risk of PCHD. However, the relationship between mental health and $\mathrm{Lp}(\mathrm{a})$ is still unknown. This study explored the association between mental health and $\mathrm{Lp}(\mathrm{a})$ levels in men with PCHD.

Methods: A retrospective, observational study was conducted. A total of 226 male patients with PCHD, aged 49.65 \pm 3.68 years, was included in this study. The control group consisted of 230 age-matched healthy male volunteers. Serum $\mathrm{Lp}$ (a) levels $\geq 30 \mathrm{mg} / \mathrm{dL}$, as measured by the immunoturbidimetry method, were considered high. All participants received health related quality of life (HRQoL) scores using the selfassessed 36-Item Short Form Health Survey (SF-36). The HRQoL includes both a physical component summary (PCS) and a mental component summary (MCS).

Results: Patients with PCHD were found to have higher levels of $\mathrm{Lp}$ (a) (51.61 \pm 33.39 vs. 26.42 \pm 21.93 , $\mathrm{P}<0.001)$, and lower MCS $(35.83 \pm 4.21 v s .39 .85 \pm 4.12)$ and PCS scores $(38.02 \pm 3.73 v s .39 .63 \pm 3.21)$ compared to healthy volunteers. The MCS score was negatively correlated with $\mathrm{Lp}$ (a) levels in the PCHD group $(\mathrm{R}=-0.295, \mathrm{P}<0.001)$, but no correlation was detected in the control group. There was no relationship between the PCS score and Lp(a) levels in neither the PCHD group nor the healthy control group. Multivariate logistic regression analysis indicated that the MCS and PCS scores were negatively correlated with the risk of PCHD.

Conclusions: These findings suggested that poor mental health may be associated with high levels of $\mathrm{Lp}(\mathrm{a})$ and increased risk of PCHD in men. Therefore, improving the mental state in men with PCHD may be crucial.

Keywords: Mental health; lipoprotein(a) levels (Lp(a) levels); premature coronary heart disease (PCHD)

Submitted Mar 24, 2021. Accepted for publication Jun 08, 2021.

doi: 10.21037/apm-21-1024

View this article at: https://dx.doi.org/10.21037/apm-21-1024 


\section{Introduction}

Lipoprotein(a) (Lp(a)) is an independent risk factor for premature coronary heart disease (PCHD) (1-5). Risk factors for premature and late-onset coronary heart disease (CHD) are different; Smoking, family history of CHD and dyslipidemia were the main risk factors for PCHD, while hypertension and diabetes were the main risk factors for the late onset of CHD (6,7). Previous studies indicated that high levels of $\mathrm{Lp}(\mathrm{a})$ have an important influence on the progress of coronary heart disease (CHD) (8). The Prospective Cardiovascular Munster Study (PROCAM) identified $\mathrm{Lp}(\mathrm{a})$ as a risk factor for early onset (age $<45$ years) myocardial infarction $(3,4)$. The Gottingen Risk Incidence and Prevalence Study (GRIP) also indicated that $\mathrm{Lp}(\mathrm{a})$ is a major cardiovascular risk factor for men aged 40 to 59 years $(4,9)$. Recent studies have shown that high levels of $\mathrm{Lp}(\mathrm{a})$ remain a cardiovascular risk factor even when low density lipoprotein cholesterol (LDL-C) levels are less than $70 \mathrm{mg} / \mathrm{dL}(10-12)$. Therefore, these studies all suggest that the residual risk of cardiovascular disease is caused by high $\mathrm{Lp}(\mathrm{a})$ levels in patients with controlled LDL-C (10).

Currently, there are few treatments available to effectively decrease Lp(a) levels $(10,13)$. Dietary control, exercise, and drugs have limited effects on $\mathrm{Lp}(\mathrm{a})$ levels $(4,13)$. Although $\operatorname{Lp}($ a) levels have been reported to be associated with daily vitamin $\mathrm{D}$ supplements and monounsaturated fatty acids, there is no clinical association between lifestyle habits and $\operatorname{Lp}($ a) levels $(10,13,14)$. The improvement of $\mathrm{Lp}$ (a) level by exercise was not consistent $(15,16)$. Exercise significantly promote serum $\mathrm{Lp}(\mathrm{a})$ concentration $(15,16)$. Another study showed that serum $\mathrm{Lp}(\mathrm{a})$ concentration did not change significantly with dietary and physical activity (17). The JUPITER (Justification for the Use of Statins in Prevention: an Intervention Trial Evaluating Rosuvastatin) study reported no significant difference in the regulation of $\mathrm{Lp}$ (a) levels with statins compared to placebo (11). A meta-analysis indicated that statins decreased LDL-C by $39 \%$ but did not affect $\mathrm{Lp}$ (a) levels (18). In a recent study, the $\mathrm{Lp}(\mathrm{a})$ levels of 3,896 patients were measured pre- and post-statin treatment. The average $\mathrm{Lp}(\mathrm{a})$ level increased by $11 \%$ after statin treatment, although some other studies have shown the increase to be as high as 50\% (10). Although, PCSK9 (proprotein convertase subtilisin/kexin type 9) inhibitors have been shown to lower LDL, studies have shown that it failed to reduce $\mathrm{Lp}$ (a) levels (19).
Interestingly, mental health has been associated with an increased risk of PCHD $(5,20)$, and significantly increased cardiovascular morbidity and mortality (20,21). Psychological factors such as emotional state and stress can affect a patient's health-related behaviors and further lead to poor medication compliance (22). The INTERHEART study, which assessed risk factors for cardiovascular disease, found that psycho-social stress is an increased risk factor for acute myocardial infarction (23). Mental disorders can also affect lipid levels. A study consisting of 92 unmedicated bipolar depression patients and 195 unmedicated unipolar depression patients found that the bipolar group had significantly lower lipid levels compared to the uni-polar group (24). Previous studies have confirmed that high levels of $\mathrm{Lp}(\mathrm{a})$ and poor HRQoL significantly increase the risk of PCHD; However, whether mental disorders affect Lp(a) levels is still unknown.

The health-related quality of life (HRQoL) assessment, as measured by the 36-Item Short Form Health Survey (SF-36) (25-27), is an individual's subjective assessment of their physical and mental health (26). The HRQoL is increasingly used as a method to evaluate the outcome of CHD (28). In patients with well-controlled traditional risk factors, low HRQoL scores significantly correlate with the increased morbidity and mortality of CHD (29). CHD patients had lower HRQoL scores compared to healthy controls. In addition, CHD patients who were wellmanaged had better HRQoL scores compared to untreated CHD patients $(25,30)$. Indeed, the HRQoL goes beyond direct traditional measures of health risk factors and commonalities in predicting cardiovascular outcomes (26). This study aimed to investigate whether mental health is associated with $\mathrm{Lp}$ (a) levels in men with PCHD. We present the following article in accordance with the STROBE reporting checklist (available at https://dx.doi. org/10.21037/apm-21-1024).

\section{Methods}

\section{Study population}

A total of 456 males who were treated in the Department of Cardiology of the Sun Yat-sen Memorial Hospital from January 2017 to January 2020 were enrolled in this retrospective study. All patients were aged 18-55 years and underwent coronary angiography. There were 226 patients diagnosed with PCHD (the PCHD group), defined as having at least one major coronary vessel stenosis 
Table 1 HRQoL scores in patients with PCHD and healthy control subjects

\begin{tabular}{lccc}
\hline Variable & PCHD group N=226 & Healthy control group, N=230 & P \\
\hline MCS & $35.83 \pm 4.21$ & $39.85 \pm 4.12$ & $<0.001$ \\
Vitality & $9.47 \pm 1.38$ & $10.15 \pm 1.12$ & $<.001$ \\
Social function & $9.85 \pm 1.38$ & $10.22 \pm 1.19$ & 0.003 \\
Role emotional & $7.48 \pm 2.37$ & $9.17 \pm 2.68$ & $<0.001$ \\
Mental health & $9.02 \pm 1.38$ & $10.32 \pm 1.07$ & $<0.001$ \\
PCS & $38.02 \pm 3.73$ & $39.63 \pm 3.21$ & $<0.001$ \\
Physical function & $10.04 \pm 0.98$ & $10.31 \pm 0.97$ & 0.002 \\
Role physical & $8.33 \pm 2.38$ & $9.0 \pm 1.81$ & 0.001 \\
Body pain & $9.83 \pm 1.18$ & $10.01 \pm 1.12$ & 0.113 \\
General health & $9.83 \pm 1.27$ & $10.32 \pm 1.12$ & $<0.001$ \\
HRQoL & $73.86 \pm 6.12$ & $79.49 \pm 6.18$ & $<0.001$ \\
\hline
\end{tabular}

HRQoL score includes both PCS and MCS, each composed of four parts. The total HRQoL score ranges from 0 (worst) to 100 (best) and includes 8 items, each of which ranges from 0 (worst) to 100 (best). The weighted standard of all 8 items are converted into a total HRQoL score out of 100 , with an average of $50 \pm 10$. HRQoL, health related quality of life; PCHD, premature coronary heart disease; PCS, physical component summary; MCS, mental component summary.

$\geq 50 \%$ (31). The average age in the PCHD group was $49.65 \pm 3.68$ years. The healthy control group included 230 healthy males without coronary vessel stenosis $\geq 50 \%$. The two groups were matched by age. Patients were excluded if they presented any of the following: congenital heart disease, cardiomyopathy, myocarditis, infective endocarditis, rheumatic heart disease, serious valvular disease, liver failure, or kidney failure. Patient characteristics including clinical history, biochemical markers, and coronary angiogram results were collected. Patient HRQoL scores were assessed using the SF-36 survey. This research conformed with the Declaration of Helsinki (as revised in 2013) and was approved by the Ethics Committee of the Sun Yat-sen Memorial Hospital, Sun Yat-sen University. Because of the retrospective nature of the research, the requirement for informed consent was waived.

\section{HRQoL and SF-36}

HRQoL was assessed using the SF-36 program for selfassessment of health status over a 4-week period $(26,32)$. The HRQoL score includes both the physical component summary (PCS) and the mental component summary (MCS), with each comprising of 4 parts (Table 1). The HRQoL assesses 8 items, with each item scoring between
0 (worst) and 100 (best). The weighted standard of the 8 items is then converted into the total HRQoL score ranging from 0 (worst) to 100 (best), with an average of $50 \pm 10$ (Table S1) $(27,33)$.

\section{Measurement of Lp(a) levels}

After fasting for 8 hours, 3-5 mL upper limb venous blood was extracted from the patient. $\mathrm{Lp}$ (a) levels were then measured by immunoturbidimetry within 2 hours, as previously described (34). Measurements $\geq 30 \mathrm{mg} / \mathrm{dL}$ are regarded as high levels of $\mathrm{Lp}(\mathrm{a})(35,36)$.

\section{Diagnosis of other risk factors}

Patients were defined as hypertensive if treatment was required or if at the second examination, mean systolic pressure was $\geq 140 \mathrm{mmHg}$ and/or mean diastolic pressure was $\geq 90 \mathrm{mmHg}$. According to the 2004 Standard of the Chinese Medical Association, hyperlipidemia was defined as total cholesterol (TC) $>5.18 \mathrm{mmol} / \mathrm{L}, \mathrm{LDL}>3.37 \mathrm{mmol} / \mathrm{L}$, and/or accepted lipid-lowering drug therapy. Diabetes mellitus (DM) was defined as fasting plasma glucose (FPG) $\geq 7.0 \mathrm{mmol} / \mathrm{L}$, plasma glucose 2 hours after a meal $\geq 11.1 \mathrm{mmol} / \mathrm{L}$, and/or accepted hypoglycemic therapy. Body mass index (BMI) was calculated as weight $(\mathrm{kg})$ divided by height square $\left(\mathrm{m}^{2}\right)$ and 
BMI $>28.0 \mathrm{~kg} / \mathrm{m}^{2}$ was considered obese.

\section{Statistical analysis}

Continuous normal distribution variables were expressed as mean \pm standard deviation and independent sample $T$-tests were used for comparison between two groups. Continuous non-normal distribution variables were expressed as median and interquartile range (IQR) and the Mann-Whitney test was used for comparison between these groups. The categorical variables were represented by numbers and percentages $\mathrm{n}(\%)$ and the Pearson chi-square test was used for comparison between groups. Spearman linear correlation was used to study the correlation between $L p(a)$ levels and HRQoL scores in the PCHD and healthy control groups. The multivariable logistic regression model was used to confirm the correlation between $\mathrm{Lp}$ (a) level, HROoL score, and PCHD risk, adjusted for diabetes, smoking, TC, LDL-C, apoliproprotein A1 (apoA1), apolipoprotein B (apoB), FBG, and BMI. Results were considered statistically significant when $\mathrm{P}<0.05$. Statistical analyses were performed using the SPSS 23.0 statistical software.

\section{Results}

\section{Clinical and biochemical characteristics}

Patients in the PCHD group and the healthy control group were age matched. The levels of $L p(a)$ in patients in the PCHD group were significantly higher compared to that observed in patients in the healthy control group $(51.61 \pm 33.39$ vs. 26.42 $\pm 21.93, \mathrm{P}<0.001$ ). In addition, patients in the PCHD group had higher BMI, TC, LDL-C, apoA1, apoB, and FBG compared to healthy controls. There were also more smokers and more diabetic patients in the PCHD group compared to the healthy control group (Table 2).

\section{HRQoL scores in the PCHD group and the bealth control group}

HRQoL was assessed using the SF-36 survey, which consisted of the MCS and PCS scores (Table 1). Patients in the PCHD group had lower MCS and PCS scores compared to healthy participants, with the exception of body pain.

\section{Linear correlation between Lp(a) levels and HRQoL scores}

Spearman linear correlation analysis showed that $\mathrm{Lp}(\mathrm{a})$ levels were negatively correlated with MCS scores in PCHD patients $(\mathrm{R}=-0.305, \mathrm{P}<0.001$; Figure 1$)$. After adjusting for risk factors, multiple linear regression analysis revealed that the MCS score was negatively correlated with $\mathrm{Lp}$ (a) levels in the PCHD group $(\mathrm{R}=-0.295, \mathrm{P}<0.001)$, but there was no association in the healthy controls (Table 3).

\section{Relationship between Lp(a) levels, HRQoL, and PCHD risk}

Multivariate logistic regression analysis showed that high HRQoL scores significantly reduced the risk of PCHD [odds ratio $(\mathrm{OR})=0.873,95 \%$ confidence interval $(\mathrm{CI})$ : 0.838 to $0.910, \mathrm{P}<0.001$ ]. However, $\mathrm{Lp}$ (a) levels (OR $=1.033$, 95\% CI: 1.024 to $1.043, \mathrm{P}<0.001$ ), Fasting blood glucose $(\mathrm{OR}=1.279,95 \% \mathrm{CI}: 1.030$ to $1.588, \mathrm{P}=0.026)$, and smoking (OR $=2.178,95 \%$ CI: 1.298 to $3.652, \mathrm{P}=0.003$ ) increased the risk of PCHD (Table 4). After adjusting for risk factors, $\mathrm{MCS}(\mathrm{OR}=0.811,95 \% \mathrm{CI}: 0.760$ to 0.860 , $\mathrm{P}<0.001)$ and PCS scores $(\mathrm{OR}=0.874,95 \% \mathrm{CI}: 0.820$ to $0.932, \mathrm{P}<0.001)$ both significantly decreased the risk of PCHD (Table 5).

\section{Discussion}

Previous studies reported that high $\mathrm{Lp}$ (a) levels was an important independent risk factor for PCHD (1-5). The PROCAM study showed that $\mathrm{Lp}$ (a) was a hazard factor for early-onset (under 45 years old) myocardial infarction (MI) $(3,4)$. The GRIP study also confirmed that high $\mathrm{Lp}$ (a) levels significantly increased cardiovascular events in men (4). Unfortunately, to date, there are few effective ways to reduce $\mathrm{Lp}(\mathrm{a})$ levels. In line with previous reports, this present study found that $\mathrm{Lp}$ (a) levels were higher in patients in the PCHD group compared to healthy subjects. Other common risk factors for PCHD in women were TC, LDL-C, autosomal dominant hyperlipidemia, PCHD family history and overweight $(37,38)$. Smoking, dyslipidemia, metabolic syndrome, and PCHD family history are the main risk factors for men (39).

Diet, exercise, and lipid-regulating drugs have limited effects on $\mathrm{Lp}$ (a) levels (4). While statins have been shown to decrease LDL-C by $39 \%$, there was little effect on $\mathrm{Lp}(\mathrm{a})$ levels (18). PCSK9 inhibitors also failed to reduce $L p(a)$ levels in the PCSK9 phase II trial (19). A meta-analysis including 2,337 patients reported that ezetimibe $(10 \mathrm{mg})$ significantly reduced plasma $\mathrm{Lp}(\mathrm{a})$ compared with placebo (40). However, another meta-analysis of 10 randomized placebo- 
Table 2 Clinical characteristics of patients with PCHD and healthy volunteers

\begin{tabular}{|c|c|c|c|}
\hline Characteristic & PCHD group, $\mathrm{N}=226$ & Healthy control group, $\mathrm{N}=230$ & $\mathrm{P}$ \\
\hline BMI (kg/m2) & $23.58 \pm 1.27$ & $23.31 \pm 1.65$ & 0.044 \\
\hline Hypertension, n (\%) & $78(34.51 \%)$ & $65(28.3 \%)$ & 0.159 \\
\hline Diabetes, n (\%) & $54(23.89 \%)$ & $35(15.2 \%)$ & 0.024 \\
\hline Hyperuricemia, n (\%) & $24(10.62 \%)$ & $20(8.7 \%)$ & 0.746 \\
\hline Smoking, n (\%) & 77 (34.07\%) & $49(21.3 \%)$ & 0.002 \\
\hline Alcohol, n (\%) & $16(7.08 \%)$ & $16(7.0 \%)$ & 1 \\
\hline PCHD family history, n (\%) & $18(7.96 \%)$ & $15(6.5 \%)$ & 0.591 \\
\hline TG (mmol/L) & $1.66 \pm 0.83$ & $1.59 \pm 0.99$ & 0.433 \\
\hline $\mathrm{HDL}-\mathrm{C}(\mathrm{mmol} / \mathrm{L})$ & $1.32 \pm 0.36$ & $1.26 \pm 0.31$ & 0.121 \\
\hline LDL-C (mmol/L) & $3.56 \pm 0.92$ & $3.08 \pm 0.90$ & $<0.001$ \\
\hline apoA1 (g/L) & $1.35 \pm 0.30$ & $1.28 \pm 0.25$ & 0.006 \\
\hline apoB (g/L) & $1.02 \pm 0.26$ & $0.90 \pm 0.25$ & $<0.001$ \\
\hline apoE (mg/L) & $37.49 \pm 11.59$ & $37.44 \pm 13.72$ & 0.973 \\
\hline $\mathrm{Lp}(\mathrm{a})(\mathrm{mg} / \mathrm{dL})$ & $51.61 \pm 33.39$ & $26.42 \pm 21.93$ & $<0.001$ \\
\hline Creatinine $(\mu \mathrm{mol} / \mathrm{L})$ & $82.73 \pm 24.04$ & $83.45 \pm 26.92$ & 0.762 \\
\hline
\end{tabular}

Results are considered statistically significant when $\mathrm{P}<0.05$. PCHD, premature coronary heart disease; BMI, body mass index; TC, total cholesterol; TG, triglycerides; LDL-C, low density lipoprotein cholesterol; HDL-C, high density lipoprotein cholesterol; FBG, fasting blood glucose ; apoA1, apolipoprotein $\mathrm{A} 1$; apoB, apolipoprotein $\mathrm{B}$; apoE, apolipoprotein $\mathrm{E}$.

controlled clinical trials (15 treatment arms) showed that ezetimibe therapy had no effect on $\mathrm{Lp}$ (a) levels (41). In the amipomersen phase III trials, amipomersen decreased $\mathrm{Lp}(\mathrm{a})$ levels at 28 weeks, but it had obvious side effects, including injection site reactions, as well as hepatic steatosis and hepatic enzyme elevation (13). While reports have shown that cholesterylester transfer protein (CETP) inhibitors can reduce $\mathrm{Lp}$ (a) levels by $25-40 \%$, it is difficult to use in clinical practice $(13,42,43)$. Although other studies have reported that daily supplements of vitamin $\mathrm{D}$ and monounsaturated fatty acids can help to decrease $\mathrm{Lp}(\mathrm{a})$ levels, there was no association between lifestyle habits and $\mathrm{Lp}$ (a) levels (13). Therefore, neither drugs nor lifestyle changes appear to be effective at reducing the levels of $L p(a)$. Of course, the role of omega-3 polyunsaturated fatty acids in the prevention of coronary heart disease remains controversial (44). Seafood and plant sources of omega-3 fatty acids concentrations of biomarkers related to reduce the incidence of fatal CHD (44); However, a study confirmed that serum fatty acid levels were not associated with coronary heart disease risk in people with low consumption of omega-3 polyunsaturated fatty acids (45).

Previous research have shown that CHD patients have lower HRQoL scores compared to healthy controls, and well-managed CHD patients have better HRQoL scores than untreated CHD patients $(25,30)$. Mental disorders were found to significantly increase the risk of $\operatorname{PCHD}(5,20)$. Furthermore, psychological intervention could effectively decrease cardiovascular mortality and morbidity $(46,47)$. 
A $\operatorname{Lp~(a)~} \mathrm{mg} / \mathrm{dL}$

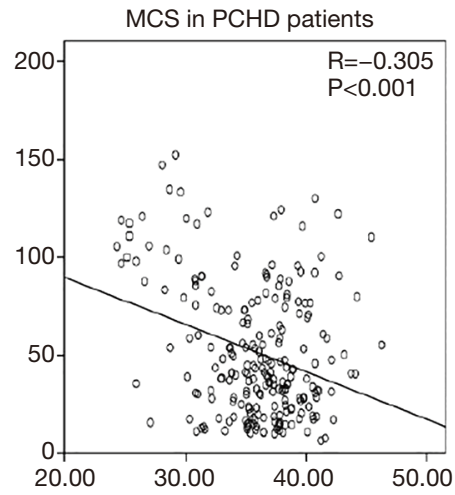

D $\mathrm{Lp}(\mathrm{a}) \mathrm{mg} / \mathrm{dL}$

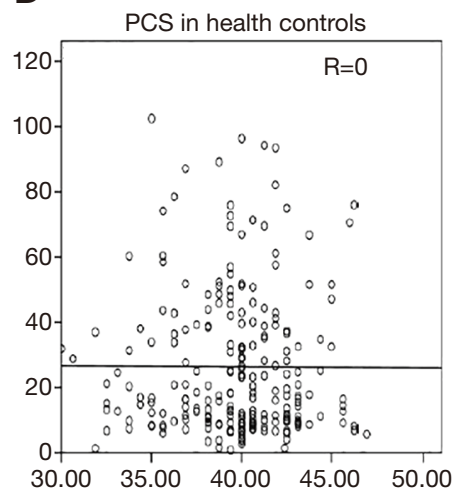

G Lp (a) mg/dL

Role emotional in $\mathrm{PCHD}$ patients

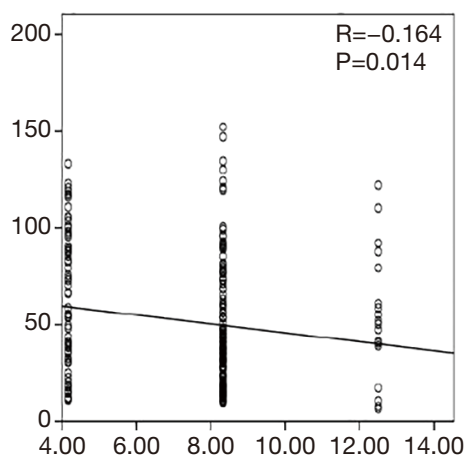

B $\quad L p(a) m g / d L$

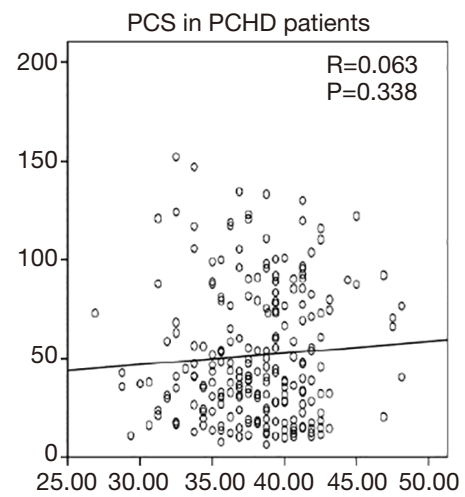

E $\quad \mathrm{Lp}(\mathrm{a}) \mathrm{mg} / \mathrm{dL}$

Vitality in $\mathrm{PCHD}$ patients

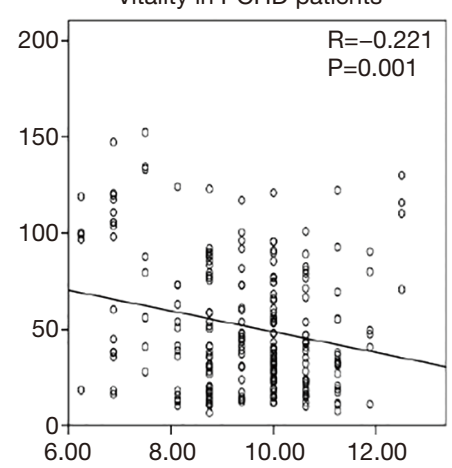

$\mathrm{H} \quad \mathrm{Lp}(\mathrm{a}) \mathrm{mg} / \mathrm{dL}$

Mental health in PCHD patients

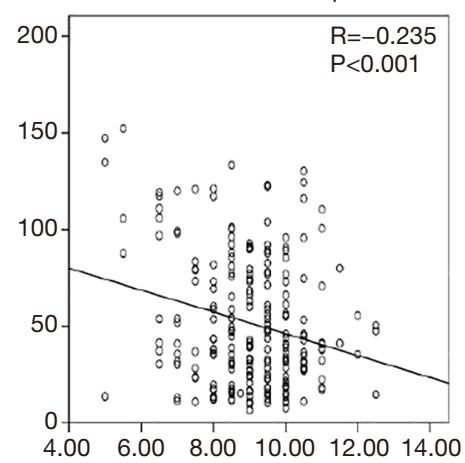

C $\quad \mathrm{Lp}(\mathrm{a}) \mathrm{mg} / \mathrm{dL}$

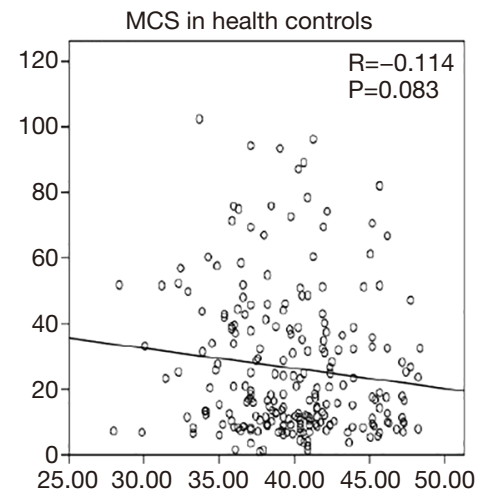

F $\quad \mathrm{Lp}(\mathrm{a}) \mathrm{mg} / \mathrm{dL}$

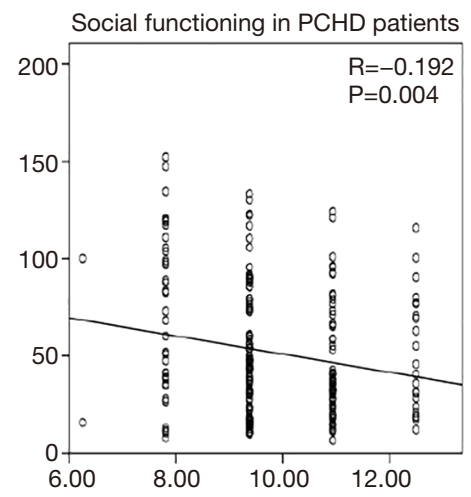

Figure 1 The linear correlation between Lp(a) and HRQoL. (A,B) In PCHD patients, Lp(a) was linearly correlated with MCS, but no correlation was observed with PCS. (C,D) In healthy control volunteers, there was no linear correlation between Lp(a) and MCS nor PCS. (E-H) In PCHD patients, Lp(a) was linearly correlated with vitality, social function, role emotional, and mental health status. Lp(a), lipoprotein(a); HRQoL, health related quality of life; PCHD, premature coronary heart disease; MCS, mental component summary; PCS; physical component summary.

In this present study, PCHD patients had lower MCS and PCS scores compared to healthy controls, which was in agreement with the former studies $(5,20,25,30)$. Although $\mathrm{CHD}$ is a candidate risk factor for dementia or cognitive impairment, there is a lack of valid evidence (48). In a meta-analysis of 10 prospective cohort studies, CHD was associated with an increased risk of cognitive impairment or dementia (49). 
Table 3 The linear correlation between Lp(a) levels and HRQoL

\begin{tabular}{|c|c|c|c|c|c|}
\hline Variable & \multicolumn{2}{|c|}{ Unstandardized coefficients } & $\frac{\text { Standardized coefficients }}{\text { Beta }}$ & $\mathrm{t}$ & $\mathrm{P}$ \\
\hline \multicolumn{6}{|l|}{ PCHD group, $\mathrm{N}=226$} \\
\hline Mental component summary (MCS) & -2.342 & 0.511 & -0.295 & -4.582 & $<0.001$ \\
\hline Vitality & -5.884 & 1.614 & -0.242 & -3.647 & $<0.001$ \\
\hline Role emotional & -1.943 & 0.957 & -0.138 & -2.031 & 0.043 \\
\hline Mental health & -5.866 & 1.595 & -0.243 & -3.670 & $<0.001$ \\
\hline Physical component summary (PCS) & 0.620 & 0.614 & 0.069 & 1.010 & 0.314 \\
\hline Physical functioning & -1.284 & 2.294 & -0.038 & -0.560 & 0.576 \\
\hline General health & 0.456 & 1.787 & 0.017 & 0.255 & 0.799 \\
\hline HRQoL & -0.907 & 0.368 & -0.166 & -2.469 & 0.014 \\
\hline \multicolumn{6}{|l|}{ Healthy control group, $\mathrm{N}=230$} \\
\hline Mental component summary (MCS) & -0.517 & 0.346 & -0.097 & -1.495 & 0.136 \\
\hline Vitality & -1.243 & 14.29 & -0.063 & -0.961 & 0.338 \\
\hline Social functioning & -1.238 & 1.210 & -0.067 & -1.023 & 0.308 \\
\hline Role emotional & -0.536 & 0.542 & -0.066 & -0.989 & 0.324 \\
\hline Mental health & -1.606 & 1.345 & -0.079 & -1.194 & 0.234 \\
\hline HRQoL & -0.253 & 0.230 & -0.071 & -1.096 & 0.274 \\
\hline
\end{tabular}

Beta as linear correlation coefficient. Lp(a), lipoprotein(a); HRQol, health related quality of life; PCHD, premature coronary heart disease; MCS, mental component summary; PCS; physical component summary.

At present, the relationship between BMI and $\mathrm{Lp}(\mathrm{a})$ is unclear. Some studies found an association in 20-29 years adults (50) and obese South Indian men (51), while no correlation was detected in women (52). This current meta-analysis showed that BMI was significantly higher in patients with PCHD compared to healthy volunteers. However, after adjusting for risk factors, BMI did not increase the risk of PCHD. This may be due to the small sample size and different ethnicities in our study cohort. Furthermore, PCS was not associated with $L p(a)$ levels in neither PCHD patients nor healthy controls, suggesting that exercise alone cannot decrease $\mathrm{Lp}$ (a) levels. Some studies have shown that $\mathrm{Lp}(\mathrm{a})$ is composed of apoA and apoB-100 (10,13). Interestingly, in our study cohort, levels of ApoA1 in patients with PCHD were significantly higher than that observed in healthy subjects.

Poor lipid control is a risk for premature coronary artery disease (53). Our previous study confirmed that low plasma HDL-C level was positively correlated with PCHD (54). Notably, there are many traditional risk factors for PCHD, 
Table 4 The relationship between Lp(a) levels, HRQoL, and PCHD risk

\begin{tabular}{lcc}
\hline Variable & OR, 95\% Cl & $P$ \\
\hline TC $(\mathrm{mmol} / \mathrm{L})$ & $0.847(0.284-2.563)$ & 0.769 \\
LDL-C (mmol/L) & $3.204(0.592-17.350)$ & 0.177 \\
ApoA1 (g/L) & $1.386(0.362-5.311)$ & 0.634 \\
ApoB (g/L) & $0.185(0.011-2.997)$ & 0.235 \\
FPG (mmol/L) & $1.279(1.030-1.588)$ & 0.026 \\
Diabetes & $0.768(0.348-1.697)$ & 0.515 \\
Smoking & $2.178(1.298-3.652)$ & 0.003 \\
BMI $(\mathrm{kg} / \mathrm{m} 2)$ & $1.074(0.912-1.265)$ & 0.390 \\
Lp(a) $(\mathrm{mg} / \mathrm{dL})$ & $1.033(1.024-1.043)$ & $<0.001$ \\
HRQoL & $0.873(0.838-0.910)$ & $<0.001$
\end{tabular}

Lp(a), lipoprotein(a); HRQol, health related quality of life; PCHD, premature coronary heart disease; TC, total cholesterol; LDL-C, low density lipoprotein cholesterol; apoA1, apoplipoprotein A1; apoB, apolipoprotein B; FPG, fasting plasma glucose; BMI, body mass index; $\mathrm{OR}$, odds ratio; $\mathrm{Cl}$, confidence interval.

Table 5 The relationship between MCS, PCS, and PCHD risk

\begin{tabular}{llc}
\hline Variable & OR, 95\% Cl & P \\
\hline MCS & $0.811(0.760-0.860)$ & $<0.001$ \\
Vitality & $0.759(0.628-0.918)$ & 0.004 \\
Social functioning & $0.941(0.791-1.120)$ & 0.494 \\
Role emotional & $0.774(0.705-0.849)$ & $<0.001$ \\
Mental health & $0.452(0.362-0.565)$ & $<0.001$ \\
PCS & $0.874(0.820-0.932)$ & $<0.001$ \\
Physical functioning & $0.745(0.594-0.935)$ & 0.011 \\
Role physical & $0.847(0.761-0.943)$ & 0.002 \\
Body pain & $0.844(0.697-1.024)$ & 0.085 \\
General health & $0.740(0.615-0.890)$ & 0.001 \\
\hline
\end{tabular}

MCS, mental component summary; PCS; physical component summary; PCHD, premature coronary heart disease; OR, odds ratio; Cl, confidence interval.

including smoking, hyperlipidemia, hypertension, and diabetes $(1,2,4,5)$. A German study found that $61 \%$ of people with PCHD were current smokers (55). In this current study, approximately $34.07 \%$ and $21.3 \%$ of PCHD patients and healthy controls were smokers, respectively. While hypertriglyceridemia is an important hazard factor for myocardial infarction in young patients (56), there was no significant difference in triglyceride levels between the PCHD group and the healthy controls in this study. The difference between our study and previous reports may be due to variations in diet across different countries and regions.

\section{Limitations}

There were several limitations to this study. Due to the cross-sectional design, it was not possible to make causal inferences regarding relationships between mental disorders and $\mathrm{Lp}(\mathrm{a})$ levels. Additionally, other undefined factors may account for both the psychological and metabolic outcomes. 
Moreover, the sample size was small in this single center study and further research involving larger cohorts are warranted.

\section{Conclusions}

In summary, this study demonstrated a significant positive correlation between poor mental health and higher $\mathrm{Lp}$ (a) levels, and PCHD risk in men. The effect of poor mental health status on $\mathrm{Lp}$ (a) levels may contribute to the development of PCHD.

\section{Acknowledgments}

The authors thank Professor Dengfeng Geng for guiding the project design.

Funding: This work was funded by Guangzhou Science Technology Bureau (202102010007); the Guangzhou Science and Technology Fund (201803040010); the National Natural Science Foundation of China (8197021630); and the Foundation and Applied Basic Research Fund of Guangdong Province (2019A1515011682).

\section{Footnote}

Reporting Checklist: The authors have completed the STROBE reporting checklist. Available at https://dx.doi. org/10.21037/apm-21-1024

Data Sharing Statement: Available at https://dx.doi. org/10.21037/apm-21-1024

Conflicts of Interest: All authors have completed the ICMJE uniform disclosure form (available at https://dx.doi. org/10.21037/apm-21-1024). The authors have no conflicts of interest to declare.

Ethical Statement: The authors are accountable for all aspects of the work in ensuring that questions related to the accuracy or integrity of any part of the work are appropriately investigated and resolved. This research conformed with the Declaration of Helsinki (as revised in 2013) and was approved by the Ethics Committee of the Sun Yat-sen Memorial Hospital, Sun Yat-sen University. Because of the retrospective nature of the research, the requirement for informed consent was waived.

Open Access Statement: This is an Open Access article distributed in accordance with the Creative Commons Attribution-NonCommercial-NoDerivs 4.0 International License (CC BY-NC-ND 4.0), which permits the noncommercial replication and distribution of the article with the strict proviso that no changes or edits are made and the original work is properly cited (including links to both the formal publication through the relevant DOI and the license). See: https://creativecommons.org/licenses/by-nc-nd/4.0/.

\section{References}

1. Emerging Risk Factors Collaboration; Erqou S, Kaptoge S, et al. Lipoprotein(a) concentration and the risk of coronary heart disease, stroke, and nonvascular mortality. JAMA 2009;302:412-23.

2. Nordestgaard BG, Chapman MJ, Ray K, et al. Lipoprotein(a) as a cardiovascular risk factor: current status. Eur Heart J 2010;31:2844-53.

3. Sandkamp M, Funke H, Schulte H, et al. Lipoprotein(a) is an independent risk factor for myocardial infarction at a young age. Clin Chem 1990;36:20-3.

4. Schatz U, Fischer S, Müller G, et al. Cardiovascular risk factors in patients with premature cardiovascular events attending the University of Dresden Lipid Clinic. Atheroscler Suppl 2019;40:94-9.

5. Burgess S, Ference BA, Staley JR, et al. Association of LPA Variants With Risk of Coronary Disease and the Implications for Lipoprotein(a)-Lowering Therapies: A Mendelian Randomization Analysis. JAMA Cardiol 2018;3:619-27.

6. Shi XJ, Li MN, Xuan L, et al. Clinical characteristics of patients with premature acute coronary syndrome and adverse cardiovascular events after PCI. Exp Ther Med 2019;18:793-801.

7. Reibis R, Treszl A, Wegscheider K, et al. Disparity in risk factor pattern in premature versus late-onset coronary artery disease: a survey of 15,381 patients. Vasc Health Risk Manag 2012;8:473-81.

8. Clarke R, Peden JF, Hopewell JC, et al. Genetic variants associated with $\mathrm{Lp}(\mathrm{a})$ lipoprotein level and coronary disease. N Engl J Med 2009;361:2518-28.

9. Cremer P, Nagel D, Labrot B, et al. Lipoprotein Lp(a) as predictor of myocardial infarction in comparison to fibrinogen, LDL cholesterol and other risk factors: results from the prospective Göttingen Risk Incidence and Prevalence Study (GRIPS). Eur J Clin Invest 1994;24:444-53.

10. Tsimikas S. A Test in Context: Lipoprotein(a): Diagnosis, 
Prognosis, Controversies, and Emerging Therapies. J Am Coll Cardiol 2017;69:692-711.

11. Khera AV, Everett BM, Caulfield MP, et al. Lipoprotein(a) concentrations, rosuvastatin therapy, and residual vascular risk: an analysis from the JUPITER Trial (Justification for the Use of Statins in Prevention: an Intervention Trial Evaluating Rosuvastatin). Circulation 2014;129:635-42.

12. Cannon CP, Blazing MA, Giugliano RP, et al. Ezetimibe Added to Statin Therapy after Acute Coronary Syndromes. N Engl J Med 2015;372:2387-97.

13. Gencer B, Mach F, et al. Potential of Lipoprotein(a)Lowering Strategies in Treating Coronary Artery Disease. Drugs 2020;80:229-39.

14. Fogacci F, Cicero AFG, D'Addato S, et al. Effect of spontaneous changes in dietary components and lipoprotein(a) levels: Data from the Brisighella Heart Study. Atherosclerosis 2017;262:202-4.

15. Ponjee GA, Janssen EM, van Wersch JW, et al. Long-term physical exercise and lipoprotein(a) levels in a previously sedentary male and female population. Ann Clin Biochem 1995;32:181-5.

16. Holme I, Urdal P, Anderssen S, et al. Exercise-induced increase in lipoprotein (a). Atherosclerosis 1996;122:97-104.

17. Mackinnon LT, Hubinger L, Lepre F, et al. Effects of physical activity and diet on lipoprotein(a). Med Sci Sports Exerc 1997;29:1429-36.

18. Willeit P, Ridker PM, Nestel PJ, et al. Baseline and onstatin treatment lipoprotein(a) levels for prediction of cardiovascular events: individual patient-data meta-analysis of statin outcome trials. Lancet 2018;392:1311-20.

19. Ray KK, Landmesser U, Leiter LA, et al. Inclisiran in Patients at High Cardiovascular Risk with Elevated LDL Cholesterol. N Engl J Med 2017;376:1430-40.

20. Gale CR, Batty GD, Osborn DP, et al. Mental disorders across the adult life course and future coronary heart disease: evidence for general susceptibility. Circulation 2014;129:186-93.

21. Lichtman JH, Froelicher ES, Blumenthal JA, et al. Depression as a risk factor for poor prognosis among patients with acute coronary syndrome: systematic review and recommendations: a scientific statement from the American Heart Association. Circulation 2014;129:1350-69.

22. Neylon A, Canniffe C, Anand S, et al. A global perspective on psychosocial risk factors for cardiovascular disease. Prog Cardiovasc Dis 2013;55:574-81.

23. Rosengren A, Hawken S, Ounpuu S, et al. Association of psychosocial risk factors with risk of acute myocardial infarction in 11119 cases and 13648 controls from 52 countries (the INTERHEART study): case-control study. Lancet 2004;364:953-62.

24. Su M, Li E, Tang C, et al. Comparison of blood lipid profile/thyroid function markers between unipolar and bipolar depressed patients and in depressed patients with anhedonia or suicidal thoughts. Mol Med 2019;25:51.

25. Sajobi TT, Wang M, Awosoga O, et al. Trajectories of Health-Related Quality of Life in Coronary Artery Disease. Circ Cardiovasc Qual Outcomes 2018;11:e003661.

26. Bonaccio M, Di Castelnuovo A, Costanzo S, et al. Healthrelated quality of life and risk of composite coronary heart disease and cerebrovascular events in the Moli-sani study cohort. Eur J Prev Cardiol 2018;25:287-97.

27. Ware JE Jr, Sherbourne CD, et al. The MOS 36item short-form health survey (SF-36). I. Conceptual framework and item selection. Med Care 1992;30:473-83.

28. Cepeda-Valery B, Cheong AP, Lee A, et al. Measuring health related quality of life in coronary heart disease: the importance of feeling well. Int J Cardiol 2011;149:4-9.

29. De Smedt D, Clays E, Annemans L, et al. Health related quality of life in coronary patients and its association with their cardiovascular risk profile: results from the EUROASPIRE III survey. Int J Cardiol 2013;168:898-903.

30. Graham MM, Norris CM, Galbraith PD, et al. Quality of life after coronary revascularization in the elderly. Eur Heart J 2006;27:1690-8.

31. Goff DC Jr, Lloyd-Jones DM, Bennett G, et al. 2013 ACC/AHA guideline on the assessment of cardiovascular risk: a report of the American College of Cardiology/ American Heart Association Task Force on Practice Guidelines. Circulation 2014;129:S49-73.

32. Jürges H, Avendano M, Mackenbach JP, et al. Are different measures of self-rated health comparable? An assessment in five European countries. Eur J Epidemiol 2008;23:773-81.

33. Matcham F, Scott IC, Rayner L, et al. The impact of rheumatoid arthritis on quality-of-life assessed using the SF-36: a systematic review and meta-analysis. Semin Arthritis Rheum 2014;44:123-30.

34. Tang Y, Geng D, et al. Associations of plasma LP(a), Hcy and D-D levels with the subtype of ischemic cerebrovascular disease. Medicine (Baltimore) 2019;98:e14910.

35. Tsimikas S, Fazio S, Ferdinand KC, et al. NHLBI Working Group Recommendations to Reduce Lipoprotein(a)Mediated Risk of Cardiovascular Disease and Aortic 
Stenosis. J Am Coll Cardiol 2018;71:177-92.

36. Anderson TJ, Grégoire J, Pearson GJ, et al. 2016 Canadian Cardiovascular Society Guidelines for the Management of Dyslipidemia for the Prevention of Cardiovascular Disease in the Adult. Can J Cardiol 2016;32:1263-82.

37. Vulic D, Loncar S, Ostojic M, et al. Risk factor indicators in offspring of patients with premature coronary heart disease in Banja Luka region/Republic of Srpska/Bosnia and Herzegovina. Arch Med Sci 2016;12:736-41.

38. Ahmad Z, Li X, Wosik J, et al. Premature coronary heart disease and autosomal dominant hypercholesterolemia: Increased risk in women with LDLR mutations. J Clin Lipidol 2016;10:101-8.e1-3.

39. Tonstad S, Svendsen M, et al. Premature coronary heart disease, cigarette smoking, and the metabolic syndrome. Am J Cardiol 2005;96:1681-5.

40. Awad K, Mikhailidis DP, Katsiki N, et al. Effect of Ezetimibe Monotherapy on Plasma Lipoprotein(a) Concentrations in Patients with Primary Hypercholesterolemia: A Systematic Review and MetaAnalysis of Randomized Controlled Trials. Drugs 2018;78:453-62.

41. Sahebkar A, Simental-Mendía LE, Pirro M, et al. Impact of ezetimibe on plasma lipoprotein(a) concentrations as monotherapy or in combination with statins: a systematic review and meta-analysis of randomized controlled trials. Sci Rep 2018;8:17887.

42. Hovingh GK, Kastelein JJ, van Deventer SJ, et al. Cholesterol ester transfer protein inhibition by TA-8995 in patients with mild dyslipidaemia (TULIP): a randomised, double-blind, placebo-controlled phase 2 trial. Lancet 2015;386:452-60.

43. HPS3/TIMI55-REVEAL Collaborative Group; Bowman L, Hopewell JC, et al. Effects of Anacetrapib in Patients with Atherosclerotic Vascular Disease. N Engl J Med 2017;377:1217-27.

44. Del Gobbo LC, Imamura F, Aslibekyan S, et al. $\omega-3$ Polyunsaturated Fatty Acid Biomarkers and Coronary Heart Disease: Pooling Project of 19 Cohort Studies. JAMA Intern Med 2016;176:1155-66.

45. Medenwald D, Kluttig A, Lacruz ME, et al. Serum dietary fatty acids and coronary heart disease risk - A nested casecontrol-study within the CARLA cohort. Nutr Metab Cardiovasc Dis 2019;29:152-8.

46. Whalley B, Rees K, Davies P, et al. Psychological interventions for coronary heart disease. Cochrane Database Syst Rev 2011;(4):CD002902.

47. Richards SH, Anderson L, Jenkinson CE, et al.
Psychological interventions for coronary heart disease: Cochrane systematic review and meta-analysis. Eur J Prev Cardiol 2018;25:247-59.

48. Deckers K, van Boxtel MP, Schiepers OJ, et al. Target risk factors for dementia prevention: a systematic review and Delphi consensus study on the evidence from observational studies. Int J Geriatr Psychiatry 2015;30:234-46.

49. Deckers K, Schievink SHJ, Rodriquez MMF, et al. Coronary heart disease and risk for cognitive impairment or dementia: Systematic review and meta-analysis. PLoS One 2017;12:e0184244.

50. Wang W, Lee ET, Alaupovic P, et al. Correlation between lipoprotein(a) and other risk factors for cardiovascular disease and diabetes in Cherokee Indians: the Cherokee Diabetes Study. Ann Epidemiol 2005;15:390-7.

51. Katsiki N, Al-Rasadi K, Mikhailidis DP, et al. Lipoprotein (a) and Cardiovascular Risk: The Show Must go on. Curr Med Chem 2017;24:989-1006.

52. Mora S, Lee IM, Buring JE, et al. Association of physical activity and body mass index with novel and traditional cardiovascular biomarkers in women. JAMA 2006;295:1412-9.

53. Froylan D MS, Esteban JG, Carlos PR, et al. Prevalence of poor lipid control in patients with premature coronary artery disease. Nutr Metab Cardiovasc Dis 2020;30:1697-705.

54. Shahid M, Sun RL, Liu Y, et al. Is high high-density lipoprotein cholesterol beneficial for premature coronary heart disease? A meta-analysis. Eur J Prev Cardiol 2016;23:704-13.

55. Lampert T, von der Lippe E, Müters S, et al. Prevalence of smoking in the adult population of Germany: results of the German Health Interview and Examination Survey for Adults (DEGS1). Bundesgesundheitsblatt Gesundheitsforschung Gesundheitsschutz 2013;56:802-8.

56. Malmberg K, Båvenholm P, Hamsten A, et al. Clinical and biochemical factors associated with prognosis after myocardial infarction at a young age. J Am Coll Cardiol 1994;24:592-9.

(English Language Editor: J. Teoh)

Cite this article as: Bao J, Zheng S, Huang J, Xie X, Zhang J, Yang S, Wu X, Zhang Y. Mental health is correlated with lipoprotein(a) levels in male patients with premature coronary heart disease. Ann Palliat Med 2021;10(6):6482-6492. doi: 10.21037/apm-21-1024 
Table S1 The 36-Item Short Form Health Survey (SF-36) (1)

\begin{tabular}{ll}
\hline HRQoL component & SF-36 questions \\
\hline Physical function (PF) & Do you think your current health condition will limit you in the following activities? If so, to what extent? \\
a. Engage in vigorous exercise, for instance running or/and lifting heavy objects; & b. Engage in moderate activities, for example moving a table, pushing a vacuum cleaner, playing bowling or golf; \\
c. Move groceries back and forth; & d. Take many stairs; \\
e. Take a few stairs; & f. Bend your waist or knees; \\
g. Walk more than a mile; & h. Walk many blocks; \\
i. Walk one block; & j. Be able to bathe or dress yourself.
\end{tabular}

Physical Role (PR)

In the past four weeks, have you experienced any of the following problems at work or in your daily activities due to your physical health?

a. Reduced time spent at work or other activities;

b. Accomplished less than you anticipated;

c. Restricted to certain work or activities ;

d. Difficulty carrying out work or other activities (does it require extra effort?).

Body pain (BP)

a. How much physical pain have you had in the past four weeks?

b. How much has the pain affected your normal work (including housework or other work) in the past four weeks?

General health $(\mathrm{GH})$
What is your general state of health?
b. I get sick more easily than others.
c. I am as healthy as anyone I know.
d. I am afraid my health will deteriorate.
e. I am in good health.

Vitality $(\mathrm{V}$

How much time in the last four weeks have you felt the following?

a. Energetic;

b. Good about your energy;

c. Exhausted;

d. A little tired;

Social function (SF)

a. To what extent has your physical health or emotional problems affected your normal social interactions with family members, friends, neighbors, or teammates in the past four weeks?

b. How often do physical or emotional problems affect your social activities (for example, visiting relatives and friends)?

Emotional role (ER)

In the past four weeks, have you experienced any of the following problems at work or in your daily life due to emotional problems (such as depression or anxiety)?

a. Reduced time spent at work or other activities;

b. Accomplished less than anticipated;

c. Not working as hard or performing usual activities.

Mental health $(\mathrm{MH})$

\section{Are you a nervous person?}

b. Do you feel so depressed that nothing can cheer you up?

c. Do you feel calm and at peace?

d. Are you feeling depressed and anxious?

e. Are you a happy person?

\section{SF-36 scores}

$P F=($ The actual score -10$) / 20 \times 100$.

a-j: Yes, very limited (1 point).

Yes, a little bit limited (2 points)

No, it's completely unlimited (3 points)

$\mathrm{R}=($ The actual score -4$) / 4 \times 100$

a-d: Yes (1 point) No (2 points)

$\mathrm{BP}=($ The actual score -2$) / 10 \times 100$

a, b: No pain/no effect on work (6 points);

Occasionally (5 points); Slightly (4 points); Moderate (3 points); Relatively serious (2 points); Extremely severe (1 point).

$\mathrm{GH}=($ The actual score -5$) / 20 \times 100$

. Wonderful ( 5 points); Very well ( 4 points); Well ( 3 points); General ( 2 points); Bad ( 1 point). $\mathrm{b}$ and d: Always true (1 point); Mostly true (2 points); Unsure (3 points); Mostly not true (4 points) Not true (5 points). c and e: Always true (5 points); mostly true (4 points); Unsure (3 points); Mostly not true (2 points); Not true (1 points).

$V=($ The actual score -4$) / 20 \times 100$

a and b: Always ( 6 points); Frequently ( 5 points); Occasionally ( 4 points); Sometimes ( 3 points); Seldom (2 points); Never (1 point). c and d: Always (1 point); Frequently (2 points);

$\mathrm{SF}=($ The actual score -2$) / 8 \times 100$

Never ( 5 points): Slightly ( 4 points): Moderate ( 3 points); Often ( 2 points); Always ( 1 point). b: Always ( 1 point); Often (2 points); Sometimes ( 3 points); Seldom ( 4 points); Never ( 5 points).

$\mathrm{R}=($ The actual score -3$) / 3 \times 100$ a-c: Yes (1 point);

No (2 points)

$\mathrm{MH}=($ The actual score -5$) / 25 \times 100$

a-c: Always (1 point): Often (2 points);

Frequently ( 3 points); Sometimes ( 4 points); Occasionally ( 5 points); Never ( 6 points). d-e: Always ( 6 points); Often ( 5 points); Frequently ( 4 points); Sometimes ( 3 points): Occasionally (2 points): Never (1 point).

$H R Q D L$, health related quality of life. 